\title{
Evaluation of the durability of asphalt mixtures depending on the physical properties of aggregates
}

\author{
Evaluación de la durabilidad de mezclas asfálticas en función de las propiedades físicas de los \\ áridos
}

Gonzalo Valdés Vidal (Main and Contact author)

Departamento de Ingeniería de Obras Civiles, Universidad de La Frontera, Francisco Salazar 01145, Temuco, Chile.

Francisco Salazar 01145, Temuco, Chile. CP: 4780000.Phone: +56 452325680

gonzalo.valdes@ufrontera.cl

Alejandra Calabi-Floody

Departamento de Ingeniería de Obras Civiles, Universidad de La Frontera, Francisco Salazar 01145, Temuco, Chile. alejandra.calabi@ufrontera.cl

\section{Elsa Sanchez-Alonso}

Departamento de Ingeniería de Obras Civiles, Universidad de La Frontera, Francisco Salazar 01145, Temuco, Chile. elsa.sanchez@ufrontera.cl

Manuscript Code: 700

Date of Acceptance/Reception: 19.08.2016/29.10.2015

DOI: $10.7764 /$ RDLC.16.1.92

\begin{abstract}
This study aims to assess the durability of asphalt mixtures through their performance versus damage by aging and water sensibility, depending on the physical properties of aggregates. Twelve types of asphalt mixtures were analyzed, using 3 types of aggregates (different shape and mineralogy), and 4 types of asphalt binders ( 2 conventional, 1 high modulus and 1 modified). The characterization of the aggregates is carried out following the protocol proposed by Zingg and the particle index (PI) according to ASTM-D3398. Both parameters have been correlated with the performance of the aggregate in the mixture. The performance of the mixtures is analyzed by the parameters of FENIX test, such as peak tensile load, stiffness rate and deformation capacity in 3 aging conditions and under wet conditions. The water sensitivity was also evaluated according to the UNE-EN12697-12. The results show that the physical characterization of the aggregates through Zingg method is not enough to predict the behavior of the mixtures studied because it considers only the coarse fraction. In turn, the results show that the angularity and surface texture of the fine fraction aggregates, analyzed through the PI parameter, has a significant effect on the performance versus moisture damage and aging of the asphalt mixtures tested.
\end{abstract}

Key words: Aggregates, physical properties, durability, asphalt mixtures, aging, moisture.

Resumen

Este estudio propone evaluar la durabilidad de mezclas asfálticas respecto de su desempeño frente al daño por envejecimiento y susceptibilidad al agua, en función de las propiedades físicas de los áridos. Se evaluaron 12 mezclas asfálticas, empleando 3 tipos de áridos (diferente forma y mineralogía), y 4 tipos de asfaltos (2 convencionales, 1 de alto módulo y 1 modificado con polímeros). La caracterización de los áridos se realiza siguiendo el protocolo propuesto por Zingg y de acuerdo al Índice de Partícula (PI) según el protocolo ASTM-D3398, parámetros que han sido correlacionados con el desempeño del árido en la mezcla. La evaluación del desempeño de las mezclas se hace a través del ensayo FENIX analizando parámetros como la carga máxima a tracción, el índice de rigidez y la capacidad de deformación; en 3 condiciones de envejecimiento y un tratamiento de inmersión. Se analizó también la sensibilidad al agua según la norma UNE-EN12697-12. Los resultados muestran que la caracterización física de los áridos por el método Zingg no es suficiente para predecir el comportamiento de las mezclas estudiadas, ya que considera sólo la fracción gruesa. A su vez, este estudio se observó que la angularidad y textura superficial de la fracción fina de los áridos, analizada a través del parámetro Pl, tiene un efecto importante en el desempeño frente al daño por humedad y al envejecimiento de las mezclas evaluadas.

Palabras clave: Áridos, propiedades físicas, durabilidad, mezclas asfálticas, envejecimiento, humedad.

Introduction

The durability of a material is directly related with its sustainability, because of a higher durability means less need of materials and energy resources for its replacement. In this context, one of the main goals of the design and construction of asphalt mixtures is to achieve more durable pavements. An asphalt mixture is essentially a mix of aggregates and asphalt binder. Both components, individually and in their interaction, play an important role in the final performance of the asphalt mixture (Valdés et al., 2015).

There are numerous studies about the influence of particle size, shape and texture of the aggregates in the performance of the mixtures. Ishai \& Gellber (1982) observed a significant increase in the stability of the mixture with an increasing irregularity of aggregates, similar to the one obtained by Oduroh et al. (2000), who concluded that 
increased crushed particles in the mixture have a significant effect in the resistance to permanent deformation, showing that a higher percentage of crushed particles leads to a higher resistance to permanent deformation. Moreno and Rubio (2013) also concluded that the nature of coarse aggregate has an important effect in the fatigue-cracking life in asphalt mixes and should be considered in mix design. Cheung \& Dawson (2002) agree that both angularity and the lack of it in the aggregates will have a strong impact on the performance of stiffness and permanent deformation, enhancing the performance of the mixture with the angularity of the particles. Regarding the shape, Kandhal \& Parker (1998) indicated that the presence of elongated and flat particles affect the durability of the asphalt mixture because such particles tend to break during the mixing, laying and pavement service. The particle size distribution and consequently the packaging of the mixture is also a property that has focused attention of researches. Several studies have assessed how it affects the shape and texture of the aggregates, the size distribution in the interaction and the load distribution generated in the mineral skeleton. In this context, numerous researchers have incorporated modelling tools, such as discrete element software and image processing techniques. For example, Shen \& Yu (2011) determined that the degree of packing of mineral skeleton of the mixture influenced the stability and mechanical performance. Dondi et al. (2012) also suggested that the degree of contact and interconnection between aggregates will depend on their shape and angularity, concluding that a higher angularity increases the interconnection and contact, improving the stress distribution, improving the mechanical performance of the mixture. Recently, Hu et al. (2015), combine real tomographic imaging processing and reconstruction of three-dimensional aggregates through finite element models, showing that the main maximum stresses are related to the size and the distribution of coarse aggregates, concentrating on the corner portions; the mastic deformation at high temperatures would be influenced by these tensions, increasing the strain in the mastic with the size of aggregates, due to higher strains. Accordingly, it is clearly shown that factors such as size, shape and texture of the aggregates are determinant on the performance of the mixture.

Similarly, the rheological properties of asphalt binder also contribute to the failure resistance by deformation or cracking. The main role of an asphalt binder is to hold together the particles (Airey et al., 2007), which is essential to ensure an adequate coverage of the aggregates in time. Furthermore, maintaining the condition of elasticity of the binder, which allows release tension by strain without reaching break, is essential. However, the organic compound of the binder affects its rheology over time due to aging (Thenoux et al., 1998; Lu \& Isacsson, 2002; Read \& Whiteoak, 2003; Lesueur, 2009). The stiffness is the main consequence of aging (Thenoux et al., 1998; Lu \& Isacsson, 2002; Lesueur, 2009), increasing the potential cracking of the asphalt mixture and decreasing the durability of the pavement (Calabi-Floody \& Thenoux, 2012).

Another failure related to the nature of the binder is moisture damage, which is associated with the loss of adhesion between the binder and the aggregates (Horgnies et al., 2011). The adhesion failure manifest when a detachment of the binder film coating the aggregates is produced (stripping), inducing a greater vulnerability of the pavement versus traffic solicitations and thermal cracking (Kim et al., 2004). The failure of the aggregate - binder links, may lead to serious damage as fatigue cracking, surface peeling and rutting (Mehrara \& Khodaii, 2013) attacking the durability of the pavement.

The goal of this research is to evaluate the effect of the physical properties of the aggregates on the durability of asphalt mixtures, through crack resistance for asphalt mixtures subjected to aging and wet conditions. Different asphalt mixtures made with three types of aggregates (AF1, AF2 and AC) were evaluated. The first two are fluvial with similar mineralogical composition but different production process. The third, quarry aggregate (AC), has different mineralogical composition, but similar shape to AF1. These aggregates will be combined with two conventional asphalt binders with different viscosity (CA14 and CA24), a modified polymer (MP) and a high modulus (AM) asphalt binders. All asphalt mixtures will be subjected to aging and water treatments, being their resistance to cracking evaluated through the Fenix test, which delivers parameters such as peak load tensile, stiffness index traction and strain, among others. Also, water sensitivity will be analyzed according to the European Standard UNE-EN 12697-12.

Materials

\section{Asphalt binders}

Four asphalt binders are used in this research: 2 conventional binders classified by viscosity (CA24 y CA14), a modified binder with SBS polymer (MP) and a high modulus asphalt binder (AM). The characterization of the asphalt binders used, according to Chilean specifications, is shown in Tables 1 and 2. 


\begin{tabular}{|c|c|c|c|}
\hline Tests & CA-24 & CA-14 & Specs. \\
\hline Absolute Viscosity at $60^{\circ} \mathrm{C}, 300 \mathrm{~mm} \mathrm{Hg}(\mathrm{P})$ & 3077 & 2226 & $(*)$ \\
\hline Ductility at $25^{\circ} \mathrm{C}(\mathrm{cm})$ & $>150$ & $>150$ & Min 100 \\
\hline Oliensis Spot Test (\% xylene) & $<25$ & $<25$ & $\operatorname{Max} 25$ \\
\hline Cleveland Open Cup Flash Poin $\left({ }^{\circ} \mathrm{C}\right)$ & 332 & 328 & Min 232 \\
\hline Softening Point $R \& B\left({ }^{\circ} \mathrm{C}\right)$ & 51 & 48.6 & $\begin{array}{l}\text { To be } \\
\text { reported }\end{array}$ \\
\hline Penetration Index & -0.7 & -0.8 & $-1.5 a+1.0$ \\
\hline \multicolumn{4}{|l|}{ RTFOT } \\
\hline Mass Loss (\%) & 0.0 & 0.1 & Max 0.8 \\
\hline \multirow[t]{2}{*}{ 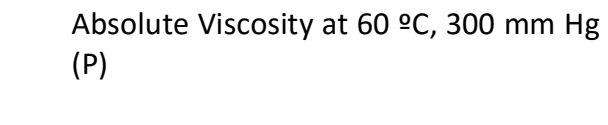 } & 7475 & 6019 & $\begin{array}{l}\text { To be } \\
\text { reported }\end{array}$ \\
\hline & $>150$ & $>150$ & Min 100 \\
\hline $\begin{array}{l}\text { Ductility at } 25^{\circ} \mathrm{C}, 5 \mathrm{~cm} / \mathrm{min} \\
\text { Durability Index }\end{array}$ & 2.4 & 2.7 & Max 3.5 \\
\hline
\end{tabular}

\begin{tabular}{|c|c|c|c|c|}
\hline Tests & MP & Specs. & AM & Specs. \\
\hline Penetration at $25^{\circ} \mathrm{C}, 100 \mathrm{~g} .5 \mathrm{~s} .(0.1 \mathrm{~mm})$ & 65 & $60-80$ & 14 & $12-17$ \\
\hline Softening Point $R \& B\left({ }^{\circ} \mathrm{C}\right)$ & 76 & Min 60 & 65 & Min. 65 \\
\hline Ductility at $5{ }^{\circ} \mathrm{C}(\mathrm{cm})$ & 52 & Min 50 & - & - \\
\hline Ductility at $25^{\circ} \mathrm{C}(\mathrm{cm})$ & 98 & Min 80 & - & - \\
\hline Penetration Index & 4.5 & Min +2 & -0.62 & Min. -1.5 \\
\hline Fraass Brittle Point $\left({ }^{\circ} \mathrm{C}\right)$ & -18 & Max -17 & -3 & Max. -5 \\
\hline Elastic Recovery $\left(13^{\circ} \mathrm{C}, 20 \mathrm{~cm}, 1 \mathrm{hr}, \%\right)$ & 66 & $\begin{array}{l}\text { To be } \\
\text { reported }\end{array}$ & - & - \\
\hline Cleveland Open Cup Flash Point (으) & 240 & Min 235 & $>240$ & Min. 240 \\
\hline Brookfield Viscosity at $135^{\circ} \mathrm{C}(\mathrm{cP})$ & - & - & 1709 & Min. 1200 \\
\hline Brookfield Viscosity at $160^{\circ} \mathrm{C}(\mathrm{cP})$ & - & - & 453.3 & Min. 350 \\
\hline \multicolumn{5}{|l|}{ RTFOT } \\
\hline Retained Penetration (\%). & & & 64 & Min. 55 \\
\hline Softening Point $R \& B$ Increase $\left({ }^{\circ} \mathrm{C}\right)$ & & & 9 & Max. 10 \\
\hline
\end{tabular}

\section{Aggregates}

This research evaluates 3 types of aggregates: 2 fluvial aggregates (AF1 y AF2), and a quarry aggregate (AC).

The fluvial aggregates differ in shape due to the production process. The AF1 and AC aggregates, whose particles are more irregular, were obtained through a cone crushing process, whereas AF2 was obtained through an impact crushing process (Figure 1). 
AF1
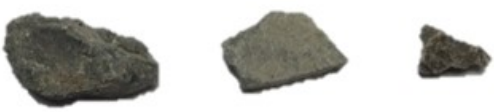

AF2
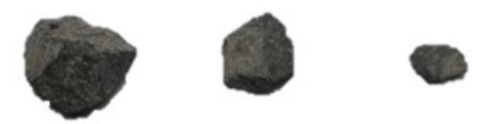

AC
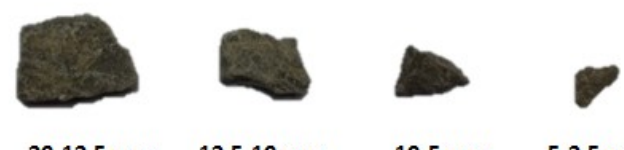

$20-12,5 \mathrm{~mm}$

$12,5-10 \mathrm{~mm}$

$10-5 \mathrm{~mm}$

$5-2,5 \mathrm{~mm}$

\section{Mineralogical and chemical compositions}

The fluvial aggregates were extracted from the same place and they are mainly composed of particles of dolomite, basalt, dacites, andesites, rhyolites, sandstone, quartz and quartzite. The quarry aggregate is mainly composed of quartz, biotite and iron oxides.The chemical analysis of the aggregate was performed by scanning electron microscopy. The results obtained are shown in Table 3.

\begin{tabular}{|c|c|c|c|c|c|c|}
\hline \multirow[b]{2}{*}{ Element } & \multicolumn{2}{|c|}{$\mathrm{AC}(\%)$} & \multicolumn{2}{|c|}{ AF1 (\%) } & \multicolumn{2}{|c|}{ AF2 (\%) } \\
\hline & Weight & Atomic & Weight & Atomic & Weight & Atomic\% \\
\hline $\mathrm{Na}$ & 5.0 & 6.4 & 2.6 & 3.4 & 5.7 & 7.2 \\
\hline $\mathrm{Al}$ & 14.3 & 15.7 & 12.8 & 14.3 & 15.3 & 16.7 \\
\hline Si & 63.3 & 66.2 & 59.9 & 64.4 & 59.1 & 62.0 \\
\hline K & 5.0 & 3.8 & 3.1 & 2.4 & 2.7 & 2.1 \\
\hline $\mathrm{Ca}$ & 5.6 & 4.1 & 6.4 & 4.8 & 6.9 & 5.1 \\
\hline $\mathrm{Fe}$ & 6.3 & 3.3 & 11.8 & 6.4 & 8.3 & 4.4 \\
\hline Total & 100 & & 100 & & 100 & \\
\hline
\end{tabular}

\section{Physical characterization}

The aggregates were characterized for their use in asphalt mixtures according to the Chilean standards (Table 4). A semi-dense type IV-A-12 gradation was selected (Table 5). The Marshall methodology was used as mix design, obtaining an optimum binder of $5.2 \% \mathrm{w} / \mathrm{a}$ for the three types of aggregates tested.

Table 4. Properties of aggregates. Source: Self-elaboration.

\begin{tabular}{lccccc}
\hline Tests & AC & AF1 & AF2 & Specifications & Method \\
\hline Los Angeles Abrasion Loss (\%) & 25 & 16 & 15 & $<25\left(^{*}\right)-35 \%$ & MC8.202.11 \\
Crushed Particles (\%) & 100 & 92 & 90 & $>90\left(^{*}\right)-70 \%$ & MC8.202.6 \\
Flaky Particles (\%) & 8 & 2.5 & 0 & $<10\left(^{*}\right)-15 \%$ & MC8.202.6 \\
& & & & & MC8.202.20 \\
Specific Gravity $\left(\mathrm{kg} / \mathrm{m}^{3}\right)$ & 2360 & 2630 & 2640 & & MC8.202.21 \\
& & & & & MC8.302.47 \\
\hline
\end{tabular}

$(*)$ Surface layer.

Table 5. Semidense type IV-A-12 aggregate gradation. Source: Self-elaboration.

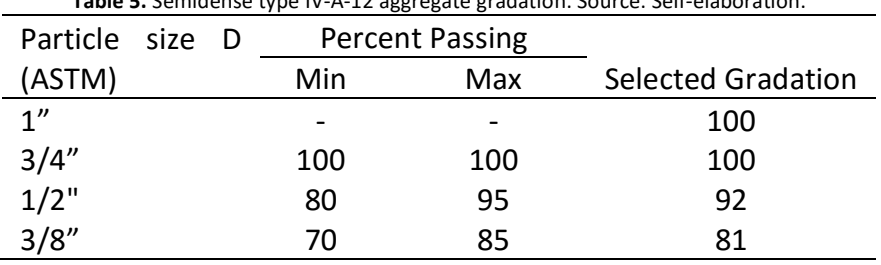




\begin{tabular}{lccc}
\hline $\mathrm{N}^{\circ} 4$ & 43 & 58 & 55 \\
$\mathrm{~N}^{\circ} 8$ & 28 & 42 & 30 \\
$\mathrm{~N}^{\circ} 30$ & 13 & 24 & 15 \\
$\mathrm{~N}^{\circ} 50$ & 8 & 17 & 10 \\
$\mathrm{~N}^{\circ} 100$ & 6 & 12 & 7 \\
$\mathrm{~N}^{\circ} 200$ & -4 & 8 & 5 \\
\hline
\end{tabular}

\section{Filler characterization}

The image analysis using light scattering was used to measure the average size of filler. This methodology is based in the acts of modification that suffers the direction and intensity of a light incident on an object, due to the combination of reflection, refraction and diffraction. The average values of the aggregates studied are $351 \mathrm{~nm}$ for $\mathrm{AC}$ aggregate and 708nm and 398nm for AF1 and AF2 aggregates, respectively.

\section{Morphology of aggregates by Zingg Method}

The Zingg method is a procedure of classifying different coarse aggregates particles by shape. This method is based on measuring the length, width and thickness of the larger particles ( $>5 \mathrm{~mm})$, to obtain four parameters: shape factor, sphericity factor, elongation and flatness ratio (Chen et al., 2005).

The Zingg diagram relates the elongation and the flatness ratio (Figure 2) and allows to define four aggregate forms: disk, rod, cubical and blade. Depending on the average particle location in the graph, the shape of the particles is determined. According to this classification, the aggregate AC is blade, AF1 and AF2 are disk and cubical type, respectively. Even though the 3 aggregates have different shapes, AC and AF1 are very close to each other.

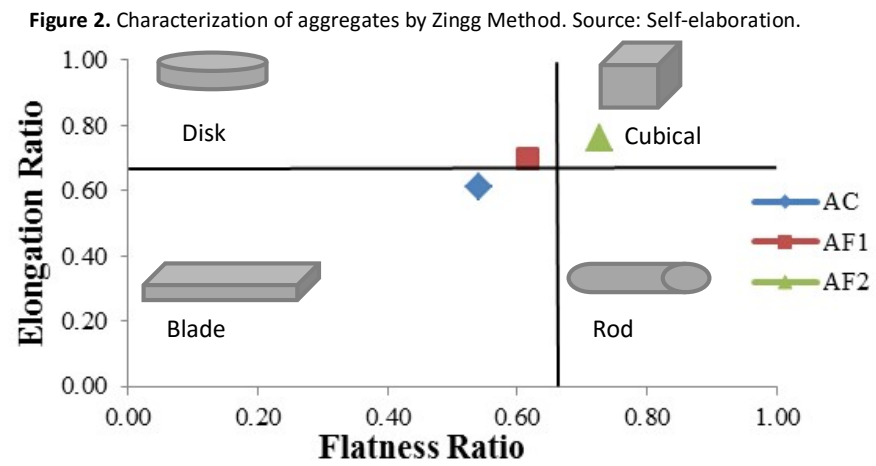

\section{Characterization of shape and texture according to particle index (PI)}

The Particle Index (PI) is a parameter described in ASTM-D3398 standard and represents the characteristics of shape and texture of the aggregates. In this research, the PI value was determined for each aggregate size of the mixture, excluding filler. The PI values were calculated according to the ASTM standard and 3 different criteria:

- Criterion I: all sizes are weighted according to their proportion in the mixture designed.

- Criterion II: only coarse aggregates are weighted according to their proportion in the mixture designed.

- Criterion III: only fine aggregates are weighted according to their proportion in the mixture designed.

According to these criteria, the PI values of the aggregates used are shown in Table 6.

\begin{tabular}{|c|c|c|c|}
\hline & $A C$ & AF1 & $\mathrm{AF} 2$ \\
\hline Criterion I & 14.3 & 16.8 & 14.1 \\
\hline Criterion II & 14.4 & 14.5 & 12.6 \\
\hline Criterion III & 14.1 & 23.0 & 17.8 \\
\hline
\end{tabular}




\section{Conditioning of the samples}

In order to evaluate the durability of the mixtures designed, the samples were subjected to aging and wet conditions prior assessment of their mechanical properties. For the aging process, the samples were heated in a forced air oven at $80^{\circ} \mathrm{C}$ for periods of 48 and 192 hours.

In the case of the wet treatments, the samples were conditioned according to the procedure described in the UNE-EN 12697-12 "Determination of the water sensitivity of bituminous specimens." The process consists in submerging the samples in distilled water at $20^{\circ} \mathrm{C}$, applying vacuum to an absolute pressure of $6.7 \mathrm{kPa}$ gradually during $10 \mathrm{~min}$, holding it for $30 \mathrm{~min}$ and recovering slowly atmospheric pressure. Then, the samples are again submerged for 30 min without pressure and finally submerged in water at $40^{\circ} \mathrm{C}$ for $72 \mathrm{~h}$ before testing.

\section{Evaluation of mechanical properties of asphalt mixtures}

The Fenix test was used to evaluate the mechanical properties of the asphalt mixtures, which is a non-traditional test developed at the Roads Lab of the Technical University of Catalonia. This test simulates the main mechanism of cracking (Mode I fracture) that the asphalt mixtures develop in the pavement structures (Valdés et al., 2009).

The test consists in applying under direct traction efforts to cause crack propagation in a fissure previously induced in a half cylindrical sample (Figure 3). The Fenix samples are attached to two steel plates, and then, prior to trial, they are conditioned to the set temperature. The plates are fixed by ball joints to the free rotation of the press pistons, which displace vertically at a constant speed of $1 \mathrm{~mm} / \mathrm{min}$. In parallel, the force and displacement data are recorded until the load decreases to the value of $0.1 \mathrm{kN}$, ending the test. Using this data, a load-displacement curve is plotted, which makes possible to obtain the mechanic parameters that characterize the crack resistance of the asphalt mixtures (Vidal et al., 2015). The main parameters obtained with the Fenix test are:

1. Peak load (Fmax) is the highest value reached by the sample due to the tensile stresses to which it is subjected, in $\mathrm{kN}$.

2. Dmdp is the displacement after peak load to $1 / 2$ Fmax, in $\mathrm{mm}$.

3. Tensile stiffness index (IRT) is an indicator of the stiffness degree of asphalt mixture (Equation 1 ).

$$
\mathrm{IRT}=\frac{1 / 2 \mathrm{Fmax}-1 / 4 \mathrm{Fmax}}{\Delta \mathrm{m}-\Delta \mathrm{c}}
$$

where:

IRT : tensile stiffness index $(\mathrm{kN} / \mathrm{mm})$

Fmax: peak load (kN)

$\Delta \mathrm{m}$ : displacement before peak load at $1 / 2 \mathrm{Fmax}(\mathrm{mm})$

$\Delta c$ : displacement before peak load at $1 / 4 \mathrm{Fmax}(\mathrm{mm})$.

Figure 3. Fenix Test Method. Source: Self-elaboration. 


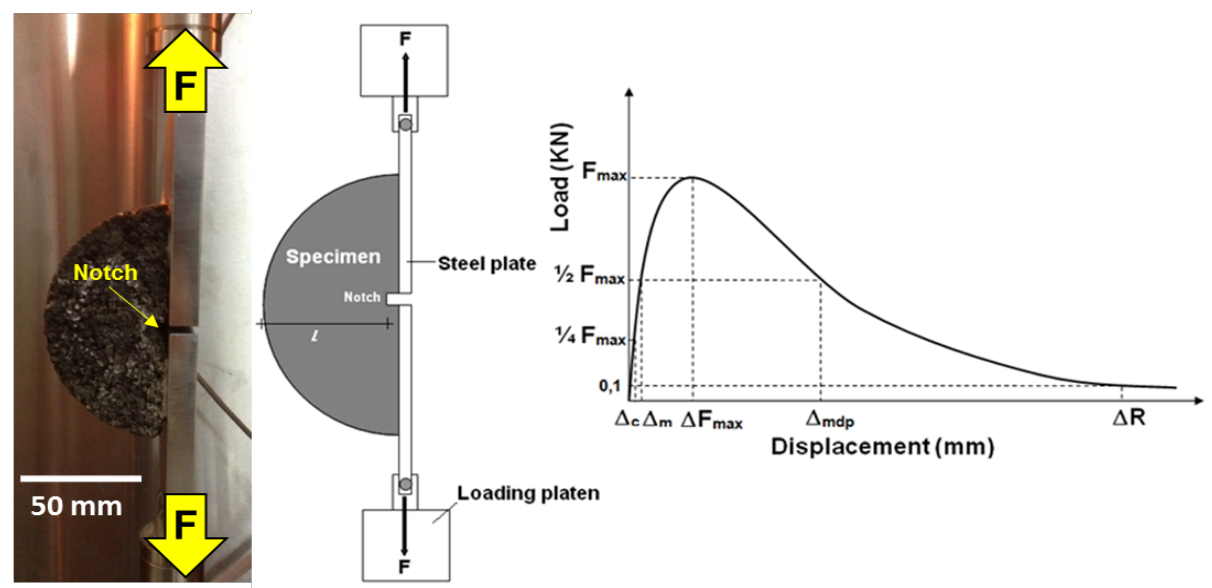

To evaluate the resistance to cracking, three samples for each combination of aggregates and binders were manufactured and tested. The temperature of testing was at $10^{\circ} \mathrm{C}$. According to the procedure of the EN 12697-12 standard (2006), a study of binder-aggregate adhesion was done. This test analyzes the impact of the saturation and immersion of the mix in water on the resistance to indirect tensile strength in Marshall-type specimens.

In this research, six specimens for each combination of aggregates and binders used were manufactured. Each group of 6 samples was separated into two groups in order to obtain a similar density. One of the groups was kept for three days at $20^{\circ} \mathrm{C}$ and the other was treated as indicated in a previous point (Conditioning of the samples). After $72 \mathrm{~h}$, the conditioned mixes were put into a room at $15{ }^{\circ} \mathrm{C}$ for two hours prior to the test. Then, an indirect tensile strength test was performed on both groups of samples, according to EN 12697-23 (2004), using a universal static machine. From the stability of the indirect tensile strength test, the resistance to traction of the wet (ITSw) and dry (ITSd) samples were calculated. The Indirect Tensile Strength Ratio (\%ITSR) was calculated according to Equation 2.

QITSR $=\frac{\text { ITSw }}{\text { ITSd }} x 100$

\section{Results and discussion}

\section{Resistance to moisture damage}

As mentioned above, the water inlet in the binder-aggregate interface deteriorates the resistance of the asphalt mixture due to the loss of adhesion of its components. This effect can happen because of the appearance of microcracks or micropores, due to the action of loads or to an increase in the stiffness of the binder, caused either by aging or by temperature, or even a combination of both (Calabi-Floody \& Thenoux, 2012). Another factor that contributes to the development of such failure is the chemical affinity between aggregates and binder, which will be more important if the aggregate is acid (Hunter et al., 2014). Moreover, cohesive failures, i.e. failures in the mastic, can also occur due to weakening links owing to different phenomena such as spontaneous emulsification (Caro et al., 2008).

The results obtained in this research shows that the moisture damage occurs in all asphalt mixtures studied. The results of asphalt mixtures made with quarry aggregates $(A C)$ have lower retention factors for maximum load and stiffness (Figure 4), while having the greatest deformation after wet treatment, compared to the asphalt mixtures made with fluvial aggregates (AF1 and AF2).

Looking at the Fmax average values obtained for the different asphalt mixtures, the load capacity decreased after the wet treatment for all asphalt mixtures (Figure 5a). However, AC asphalt mixtures showed greater susceptibility to moisture damage by reducing its loading capacity between 29 and 63\%, approximately. The AF1 and AF2 asphalt mixtures have displayed a similar behavior, showing a decrease of the load capacity after wet treatment of between 7 and $15 \%$ for mixtures with AF1 and 4 and $19 \%$ for mixtures with AF2. In this case, the mineralogical and chemical composition of the aggregates may prevail over the morphology of coarse aggregates, because the asphalt mixtures made with fluvial aggregates, with similar mineralogical composition but different coarse aggregate morphology, 
showed similar behavior. Taking into account the chemical composition of aggregates (Table 3), the AC aggregates presented higher silica content compared to AF1 and AF2, showing worse results under wet conditions. These results agree with the studies of Hunter et al. (2014) which indicated that the aggregates with higher silica content are hydrophilic, submitting major problems due to poor adhesion affinity of the binder with this type of aggregates.

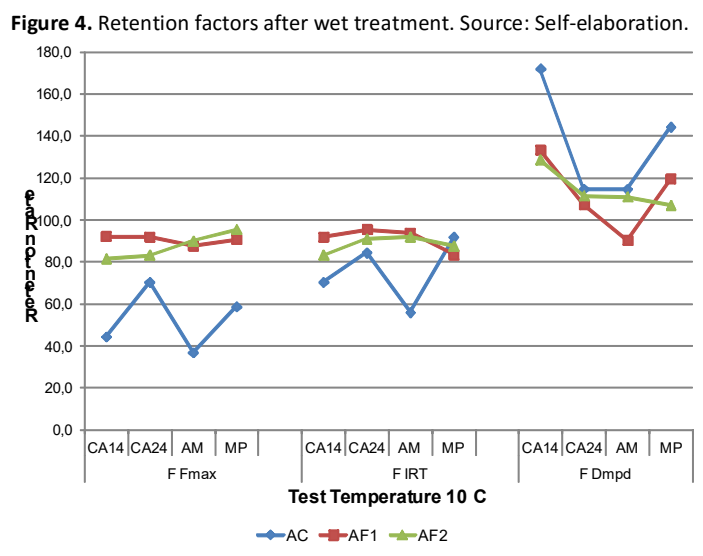

The stiffness results obtained showed similar trends to the Fmax ones (Figure 5b). All asphalt mixtures diminished their stiffness after the wet treatment. The AC asphalt mixtures were the most affected, presenting lower stiffness values under wet conditions (between 8 and 44\%) than AF1 and AF2 asphalt mixtures, which presented a reduction of stiffness between $4-23 \%$ and $8-12 \%$, respectively (Figure $5 \mathrm{~b}$ ). As it can be observed in Figure 2, the shape of AF1 and AF2 aggregates differs according to the Zingg criterion (disk and cubical, respectively); but for both types of aggregates, the PI values considering the fine fraction (criterion III), are very high, 23.0 and 17.8 respectively (Table 6), indicating that the fine fraction of these mixtures has a high angularity and surface texture providing contact points and contributing to the distribution of loads agreeing with Hu et al. (2014). So, the resistance of the mineral aggregate interlock after the wet treatment would be favored. This phenomenon can also be seen in the deformation exhibited by the asphalt mixtures (Figure $5 \mathrm{c}$ ), which increased in all cases tested, being more sensitive for the $A C$ asphalt mixtures (14-72\%) than for AF1 and AF2 mixtures (7-33\%, 7-28\%, respectively). These results can be explained by the internal interlocking generated by the high angularity of the fine matrix in AF1 and AF2 asphalt mixtures, that would maintain this condition, even when the binder suffered the effects of moisture damage. When assessing this parameter (Dmdp), it is interesting to note that the increase in the susceptibility to moisture damage occurs in asphalt mixtures with soft binders (CA14 and MP), but this damage is lessened in the AF1 and AF2 asphalt mixtures, due to the interlocking contribution generated by the angularity of its fine matrix (Figure $5 \mathrm{c}$ ).

Analyzing the average of the results obtained to evaluate water sensitivity of asphalt mixtures (Figure 6), it can be seen that the behavior shown in both wet and dry samples was similar to the one obtained in the specimens tested with the Fenix method (Figure 5).

The samples manufactured with AC aggregate had lower values of tensile strength compared to fluvial mixes, because its $\mathrm{PI}$ value of the fine fraction (Criterion III) was lower than in the case of the fluvial aggregates, indicating that this fraction of the AC aggregates had a lower angularity and surface texture, reducing the contact points and resulting in a worse load distribution. In turn, AC mixtures showed a further decrease of the tensile strength value after wet treatment with AF1 and AF2 mixtures for all types of binders used, so the influence of the nature of the aggregate is obvious, since this aggregate is more hydrophilic because of its higher silica content (Table 3 ). These results confirm the results of the Fenix test (Figure 5).

The behavior of AF1 mixtures shows a closer behavior to AF2 mixtures than to those of AC, so concluding that the nature of the aggregate has more influence than its shape, confirming the results obtained with Fenix test (Figure 5). 


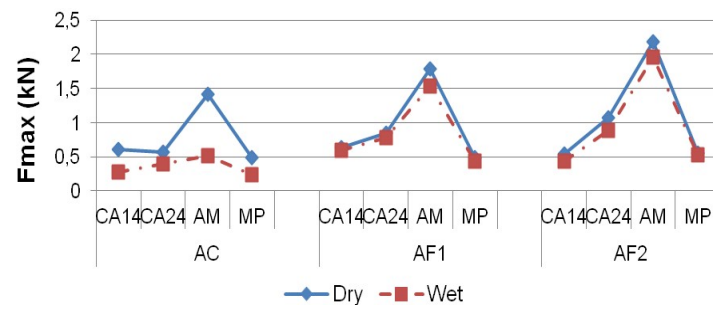

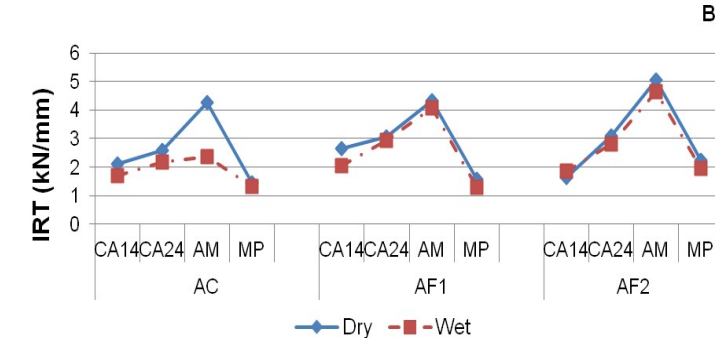

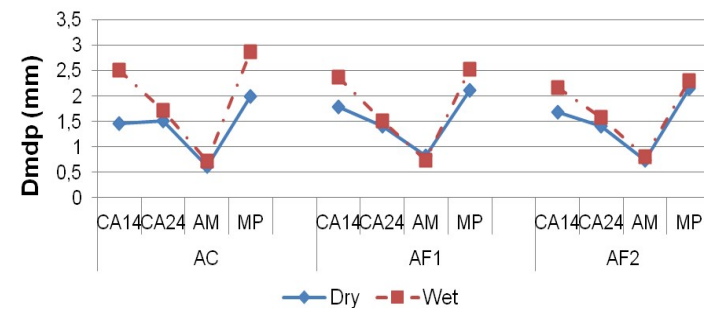

To evaluate the relationship between the resistance of both groups of conditioned samples (wet and dry), the Spanish standard is considered because it is based in European regulations. In Spain, the regulation requires a water resistance of at least $85 \%$ for mixtures for surface layer, and $80 \%$ in the case of base or intermediate layers, tested at $15^{\circ} \mathrm{C}$ (Ministerio de Fomento, 2015). Considering the \%ITSR values (Figure 6), all asphalt mixtures made with AM binder, which is the hardest one (Tables 1 and 2), have lower water resistance without reaching the limits established the Spanish standards. 


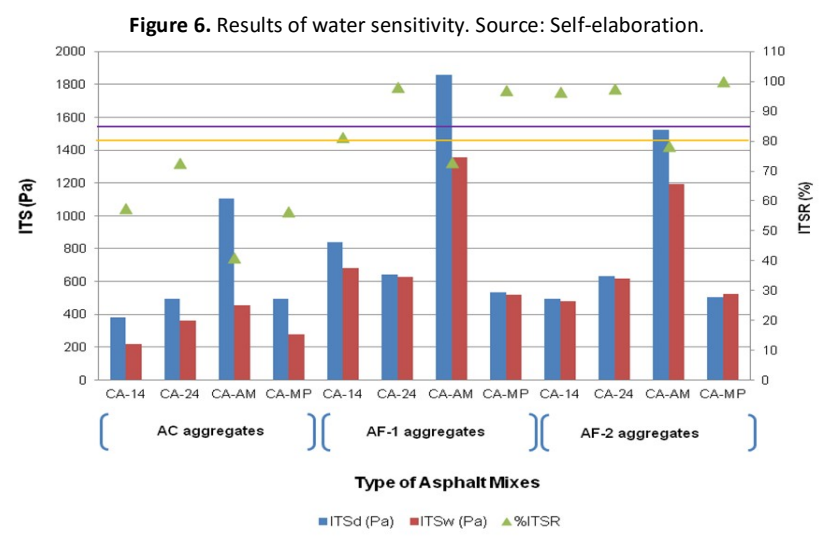

In addition, all AC asphalt mixtures have lower water resistance compared to the fluvial aggregate mixtures, unfulfilling the Spanish standard for any of the pavement layers. For both types of fluvial aggregates, the CA-24 and MP binders could be employed for the surface layer according to the Spanish standard. In the case of the AF2 mixture, CA-14 could also be used in surface layer, but for AF1 it could only be used in intermediate or base layers (Figure 6).

\section{Resistance to aging}

As expected, all asphalt mixtures increased their tensile strength after the aging treatment because of stiffening (Figure 7a). The AC asphalt mixtures increased their tensile strength between 1.2 and 2.5 times, indicating that they are more susceptible to aging than the mixtures made with fluvial aggregates. The AF1 and AF2 asphalt mixtures also increased their values of tensile strength, but these increases were smaller than in AC mixtures, reaching values of Fmax between 1.2 and 1.7 times higher after 2 days of aging for AF1 and between 1.15 and 1.9 times for AF2 (Figure 7a). Comparing these results with the deformation capacity of asphalt mixtures, Figure $7 \mathrm{~b}$ shows that the mixtures with fluvial aggregates (AF1 and AF2) possessed higher tensile strength after aging but maintaining a higher deformation capacity, inferring a better performance. The results also showed that the softer binders had greater susceptibility to aging while the high modulus binder hardly varied with respect to its strength and deformability (Figures $7 \mathrm{a}$ and $7 \mathrm{~b}$ ).

Figure 7. Aging effect: (a) Maximum tensile load (Fmax), (b) Displacement after peak load to $1 \frac{12}{2} \mathrm{max}(\mathrm{mm})$ and (c) Tensile stiffness index. Source: Self-elaboration.
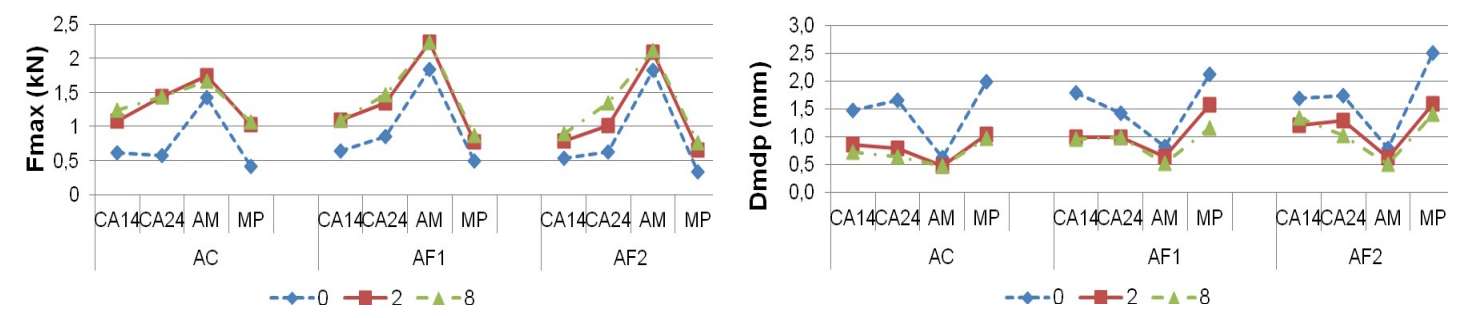

C

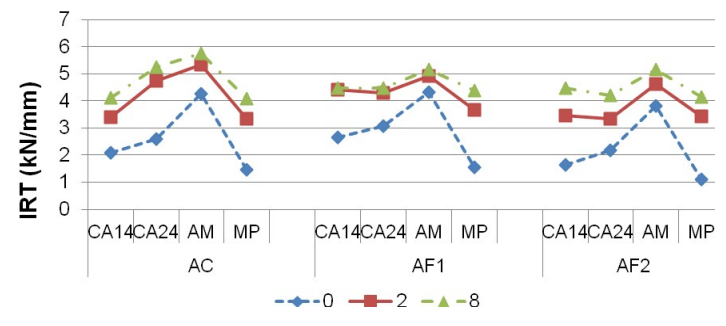

Analyzing the evolution of the stiffness post aging treatments (Figure 7c), the stiffness of the asphalt mixtures with AC aggregates increased even more, while fluvial asphalt mixtures were less susceptible to stiffening by aging. This could be related to the angularity and texture of fine matrix of fluvial aggregates with high PI values (Table 6), generating a 
more interconnected mineral skeleton, slowing down the diffusion of oxygen into the mixture, and reducing their vulnerability to aging.

In this research, the different behavior of asphalt mixtures manufactured with several types of aggregates was studied, showing that the role of the aggregates in the performance and durability of an asphalt mixture is critical. The morphology of the aggregates could not be linked to the performance against moisture damage or aging of the asphalt mixtures; but it was established that the texture and angularity of the fine fraction of the aggregates plays an important role in resistance to damage by aging or/and by water effect, related to high PI values according to Criterion III, showing better performance the fluvial aggregates. The softer binders showed an increase susceptibility to moisture damage and aging, being this effect lower on those asphalt mixtures whose aggregates had high PI value according to Criterion III defined in this study.

\section{Acknowledgments}

The present article is the result of the research supported by CONICYT program, conducted within the framework of the FONDECYT INICIACION Project № 11130723.

References

Airey, G. D., Choi, Y. K., Collop, A. C., Moore, A. J. V, Elliott, R. C., Ishai, I., ... Davis, R. (2005). Combined laboratory ageing / moisture sensitivity assessment of high modulus base asphalt mixtures. In Proceedings - Association of Asphalt Paving Technologists, Technical Sessions (Vol. 74, pp. 307-345).

Calabi-Floody, A., \& Thenoux, G. (2012). Controlling asphalt aging by inclusion of byproducts from red wine industry. Construction and Building Materials, 28(1), 616-623. https://doi.org/10.1016/j.conbuildmat.2011.08.092

Caro, S., Masad, E., Bhasin, A., \& Little, D. N. (2008). Moisture susceptibility of asphalt mixtures, Part 1: mechanisms. International Journal of Pavement Engineering, 9(2), 81-98. https://doi.org/10.1080/10298430701792128

Chen, J.-S., Chang, M. K., \& Lin, K. Y. (2005). INFLUENCE OF COARSE AGGREGATE SHAPE ON THE STRENGTH OF ASPHALT CONCRETE MIXTURES. Journal of the Eastern Asia Society for Transportation Studies, 6, 1062-1075.

Cheung, L. W., \& Dawson, A. (2002). Effects of Particle and Mix Characteristics on Performance of Some Granular Materials. Transportation Research Record: Journal of the Transportation Research Board, 1787, 90-98. https://doi.org/10.3141/1787-10

Dondi, G., Simone, A., Vignali, V., \& Manganelli, G. (2012). Discrete Element Modelling of Influences of Grain Shape and Angularity on Performance of Granular Mixes for Asphalts. Procedia - Social and Behavioral Sciences, 53, 399-409. https://doi.org/10.1016/j.sbspro.2012.09.891

Horgnies, M., Darque-Ceretti, E., Fezai, H., \& Felder, E. (2011). Influence of the interfacial composition on the adhesion between aggregates and bitumen: Investigations by EDX, XPS and peel tests. International Journal of Adhesion and Adhesives, 31(4), 238-247. https://doi.org/10.1016/j.ijadhadh.2011.01.005

Hunter, R. N., Self, A., Read, J., Gerlis, R., Taylor, R., Hobson, E., \& Shell Bitumen (Firm). (2014). The Shell bitumen handbook (Sixth Edit). London, UK: ICE Publishing.

Ishai, I., \& Gelber, H. (1982). Effect of geometric irregularity of aggregates on the properties and behavior of asphalt concrete. In Transportation Research Board (Vol. 51, pp. 494-521).

Kandhal, P. S., \& Parker, F. J. (1998). NCHRP 405. Aggregate tests related to asphalt concrete performance in pavements. Washington, D.C: Retrieved from http://onlinepubs.trb.org/onlinepubs/nchrp/nchrp_rpt_405.pdf

Kim, Y.-R., Little, D., \& Lytton, R. (2004). Effect of Moisture Damage on Material Properties and Fatigue Resistance of Asphalt Mixtures. Transportation Research Record: Journal of the Transportation Research Board, 1891(1891), 48-54. https://doi.org/10.3141/1891-07

Lesueur, D. (2009). The colloidal structure of bitumen: Consequences on the rheology and on the mechanisms of bitumen modification. Advances in Colloid and Interface Science, 145(1-2), 42-82. https://doi.org/10.1016/j.cis.2008.08.011

Lu, X., \& Isacsson, U. (2002). Effect of ageing on bitumen chemistry and rheology. Construction and Building Materials, 16(1), 15-22. https://doi.org/10.1016/S0950-0618(01)00033-2

Mehrara, A., \& Khodaii, A. (2013). A review of state of the art on stripping phenomenon in asphalt concrete. Construction and Building Materials, 38, 423-442. https://doi.org/10.1016/j.conbuildmat.2012.08.033

Ministerio de Fomento. (2015). Pliego de prescripciones técnicas general para obras de carreteras y puentes (PG-3). Madrid: Centro de publicaciones Secretaría General Técnica Ministerio de Fomento. Retrieved http://www.fomento.gob.es/MFOM.CP.Web/handlers/pdfhandler.ashx?idpub=ICW020 
Moreno, F., \& Rubio, M. C. (2013). Effect of aggregate nature on the fatigue-cracking behavior of asphalt mixes. Materials \& Design, 47, 61-67. https://doi.org/10.1016/j.matdes.2012.12.048

Oduroh, P. K., Mahboub, K. C., \& Anderson, R. M. (2000). Flat and Elongated Aggregates in Superpave Regime. Journal of Materials in Civil Engineering, 12(2), 124-130. https://doi.org/10.1061/(ASCE)0899-1561(2000)12:2(124)

Read, J., Whiteoak, D., \& Shell Bitumen (Firm). (2003). The Shell bitumen handbook (Fifth Edit). London, UK: Shell Bitumen.

Shen, S., \& Yu, H. (2011). Characterize packing of aggregate particles for paving materials: Particle size impact. Construction and Building Materials, 25(3), 1362-1368. https://doi.org/10.1016/j.conbuildmat.2010.09.008

Thenoux, G., Bell, C. A., \& Wilson, J. E. (1988). Evaluation of physical and fractional properties of asphalt and their interrelationship. Transportation Research Board, (1171), 82-97.

Valdés, G., Pérez-Jiménez, F., \& Botella, R. (2009). Ensayo Fénix, una Nueva Metodología para Medir la Resistencia a la Fisuración en Mezclas Asfálticas. Revista De La Construcción, 8(1), 114-125.

Valdés Vidal, G., Miró Recasens, R., \& Martínez Reguero, A. (2015). Assessment of the adhesive capacity of asphalt binders in the aggregate-binder bonds by means of new methodology. Revista de La Construcción, 14(1), 69-76. https://doi.org/10.4067/S0718-915X2015000100009 